http://jmscr.igmpublication.org/home/ ISSN (e)-2347-176x ISSN (p) 2455-0450 crossref DOI: https://dx.doi.org/10.18535/jmscr/v8i11.34

\title{
Comparison of Magnesium Sulphate and Dexmeditomidine as an Adjuvant to 0.5\% Ropivacaine in Infraclavicular Brachial Plexus Block
}

\author{
Authors \\ Dr Jipal G. Prajapati ${ }^{1}$, Dr Dipak Raval ${ }^{2}$ \\ 1Third Year Resident, Department of Anaesthesia, Shri M.P. Shah Government Medical College, Guru \\ Gobind Singh Hospital, Jamnagar, Gujarat, India \\ ${ }^{2}$ Additional Professor, Department of Anaesthesia, Shri M.P. Shah Government Medical College, Guru \\ Gobind Singh Hospital, Jamnagar, Gujarat, India
}

\begin{abstract}
Background and Aims: The comparison of dexmeditomidine and magnesium sulphate for sedation and post-operative analgesia as an adjuvant to Ropivacaine $0.5 \%$ in Infraclavicular block.

Materials and Methods: Aprospective, randomized, double blind study was conducted on 60 patients of American society of Anaesthesiologists physical status I,II,III aged between 18 to 60 years, weighing between 30 to $90 \mathrm{~kg}$ posted for upper limb surgeries under infraclavicular block. The patients were randomly allocated into two groups of 30 each to receive either $35 \mathrm{ml}$ of inj ropivacaine $0.5 \%$ with inj Megnesium sulphate $(150 \mathrm{mg}) 1.5 \mathrm{ml}$ with $2.5 \mathrm{ml} 0.9 \%$ normal saline (total volume $39 \mathrm{ml}$ ) group MS or 35 $\mathrm{ml}$ of inj. Ropivacaine 0.5\% with inj. Dexmeditomidine $(100 \mu \mathrm{g}) 1 \mathrm{ml}$ with $3 \mathrm{ml}$ of $0.9 \%$ normal saline (total volume $39 \mathrm{ml}$ ) group $\mathrm{D}$. The onset time of sensory block and motor block, duration of surgery, duration of motor blockade and post-operative analgesia, visual analog scale score, compare sedation score, vital parameters, and adverse effects compared between these two groups.

Results: The mean duration of surgery in group MS was longer( $84.33 \pm 22.69 \mathrm{~min})$ compared to group $D$ $(96 \pm 17.73 \mathrm{~min})$, The mean onset time of complete sensory and motor bock in group MS was longer (17.33 $\pm 1.49 \mathrm{~min} ; 21.33 \pm 1.75 \mathrm{~min})$ compared to group $D(7.6 \pm 1.329 \mathrm{~min} ; 10.2 \pm 1.67 \mathrm{~min})$, total duration of sensory and motor block in group MS was shorter (349 $\pm 25.91 \mathrm{~min} ; 288 \pm 26.35 \mathrm{~min})$ as compared to group D (590.33 $\pm 27.97 \mathrm{~min} ; 398.66 \pm 26.48 \mathrm{~min})$, The mean duration of analgesia was longer in group $D$ $(664.33 \pm 30.02 \mathrm{~min})$ as compared to group in $\mathrm{MS}(386 \pm 30.69 \mathrm{~min})$.all results were statistically significant $(P<0.001)$. No significant side effects were observed in any of the two groups.

Conclusion: Inj. Dexmeditomidine as an adjuvant to Inj. Ropivacaine compared to Magnesium sulphate as an adjuvant to Inj. Ropivacine in Infraclavicular brachial plexus block for upper limb surgery fastens the onset time for sensory and motor block and prolongs the duration of sensory and motor blocks with longer duration of postoperative analgesia.

Keywords: Analgesia, Dexmeditomidine, Magnesium sulphate, Ropivacaine, Infraclavicular brachial plexus.
\end{abstract}

\section{Introduction}

Regional anesthesia is an important part of the anesthesiologist's armamentarium. Regional anesthesia is particularly indicated for patients undergoing peripheral limb surgery because it provides effective intraoperative anaesthesia and 
post-operative pain control. Brachial plexus block is a versatile and reliable regional anaesthetic technique and a suitable alternative to general anesthesia for upper limb surgical procedures. Infraclavicular approach of brachial plexus block is the commonly used approach and provides the most complete and reliable anaesthesia for upper limb surgery. The Infraclavicular approach is a regional anesthetic technique designed to prevent the side effects and complications of supraclavicular blocks, particularly pneumothorax. For brachial plexus block, a drug that has a fast onset, long duration, and minimal toxicity could be an advantage. The quest for safer local anesthetics began toward the end of the 19th century. ${ }^{[1]}$

Ropivacaine is a long-acting local anesthetic drug belonging to aminoamide group. They are pure $\mathrm{S}(-)$ enantiomer, unlike bupivacaine which is a racemic mixture. These $\mathrm{S}$ enantiomers are considered to produce less neurotoxicity and cardiotoxicity than racemic mixtures or the Renantiomers of local anesthetics. Local anesthetics alone for Infraclavicular brachial plexus block provide good operative conditions but have a shorter duration of post-operative analgesia. Hence, various drugs such as opioids, clonidine, dexmeditomidine, dexamethasone, midazolam, and magnesium sulphate were used as an adjuvant with local anaesthetics in brachial plexus block.

Magnesium is a physiological calcium channel blocker and has also $\mathrm{N}$-methyl - D -aspartate (NMDA) receptor antagonist effect since magnesium sulphate can prevent central sensitization by the peripheral nociceptive stimulation, it can be used as adjuvant local anesthetic solution for different kinds of regional anesthesia and analgesia to improve the quality andprolong duration of the block.

Dexmeditomidine is highly selective $\alpha 2$ Adrenergic agonist more potent and faster than clonidine. It has Analgesic, sedative, antihypertensive, and anaesthetic sparing effect; when added to local anaesthesia for regional or peripheral nerve block, it prolongs the duration of the block and postoperative analgesia. ${ }^{[2]}$

The aim of our study was to evaluate and compare the effect of Magnesium sulphate and Dexmeditomidine as an adjuvant to Inj. Ropivacaine $0.5 \%$ for Infraclavicular block on the duration of analgesia, and the onset times and durations of sensory block and motor block and patient's satisfaction.

\section{Materials and Methods}

After approval of the institutional ethical committee, this prospective, double-blind, randomized trial was conducted on 60 patients of the American Society of Anesthesiologists physical Status I II and III of both genders, aged 18-60 years, scheduled for various upper limb surgeries after obtaining written informed consent from each patient. Patients who had not given consent, patients with coagulopathy, infection at the site of block, preexisting peripheral neuromuscular disease, and allergy to any of the study drugs, i.e., Dexmeditomidine, Magnesium sulphate or Ropivacaine were excluded from study.

The patients were randomly allocated into two groups of 30 each using computer-generated table of random numbers. The allocation concealment was done using sequentially numbered closed opaque-sealed envelope technique. Group MS received $35 \mathrm{ml}$ of $0.5 \%$ Ropivacaine with $1.5 \mathrm{ml}$ (150 mg) Magnesium sulphate with $2.5 \mathrm{ml} \mathrm{0.9 \%}$ normal saline and Group D received $35 \mathrm{ml}$ of $0.5 \%$ Ropivacaine with $1 \mathrm{ml}(100 \mu \mathrm{g})$ of Dexmeditomidine with $3 \mathrm{ml} 0.9 \%$ normal saline (total volume is $39 \mathrm{ml}$ in both groups). A resident anesthesiologist, who was not involved in the study process, prepared the syringes loaded with the study drugs for Infraclavicular block and the another anesthesiologist who performed the block and observed the patient thereafter was unaware of the contents of the loaded syringes for the purpose of double blinding so both the anesthesiologists who prepared the drugs and the 
observer who performed the block as well as assessed the results, were blinded.

Pre-anaesthetic assessment was done on evening before surgery. A routine examination was done by assessing general condition, nutritional status, weight, airway assessment, complete examination of cardiovascular, respiratory system, site of block, and investigation in all patients. All patients were kept electively nil per oral $6 \mathrm{~h}$ before surgery and before operation patients were explained about the procedure and a written informed consent taken. Intravenous line secured. Standard monitors such as electrocardiogram, pulse oximeter, and blood pressure cuff were applied, and patient's baseline parameter such as pulse, blood pressure, respiratory rate, and $\mathrm{SpO} 2$ was recorded. All patients were premedicated with (on operation table):

- Injection Glycopyrrolate $0.2 \mathrm{mg}$ IV slowly

- Injection Ondansetron 4 mg IV slowly

- Injection Midazolam 1 mg IV slowly

For performing brachial plexus blockade through Infraclavicular approach, we used classical (RAJ) technique. The patients were placed in the recumbent position with the head turned away from the site of brachial block, under all aseptic and antiseptic precautions The subclavian artery is palpated or the midpoint of the clavicle is marked. The brachial artery is palpated and marked at lateral border of the pectoralis muscle. A line joining these two points is made, a 23G 1.5 inch needle was introduced at $2.5-3 \mathrm{~cm}$ below the midpoint of clavicle at 45 to 60 degree toward axillary artery. The first two fingers of the palpating hand anchor the skin at the point of insertion, needle is advanced at 45-66 degree toward the brachial pulsation or parallel to a line connecting the medial clavicular head with the coracoid process if pulsation can't be felt. Here, local anaesthetic solution is injected. Before every incremental dose, negative aspiration for blood was performed to avoid any intravascular injection. $^{[3]}$

End of the injection was taken as time " 0 ." Immediately after the block, sensory and motor characteristics of blockade, hemodynamic variables, and $\mathrm{SpO} 2$ were assessed at $5,10,15,20,25$, and $30 \mathrm{~min}$ and then $10 \mathrm{~min}$ for 1 hour, than $20 \mathrm{~min}$ for 1 hour, than $30 \mathrm{~min}$ for 1 hour till offset of sensory and motor blockade.

Sensory block was assessed by pinprick test using a needle at each minute after the completion of drug injection in the corresponding dermatomal areas till complete blockade.

The sensory and motor characteristics of the block

\section{Sensory Characteristics}

- Onset - It was taken as time duration from the end of injection to dull response to pin prick.

- Duration - It was taken as time duration from complete sensory block to feeling of pinprick sensation.

\begin{tabular}{|l|c|c|c|}
\hline \multicolumn{4}{|c|}{ Table 2 Sensory Characteristics of Brachial Plexus Blockade } \\
\hline $\begin{array}{l}\text { sensory characteristics } \\
(\mathrm{min})\end{array}$ & $\begin{array}{c}\text { Group MS }(\mathbf{n}=\mathbf{3 0}) \\
(\text { mean } \pm \text { SD })\end{array}$ & $\begin{array}{c}\text { Group D }(\mathbf{n}=\mathbf{3 0}) \\
(\text { mean } \pm \text { SD })\end{array}$ & P value \\
\hline Onset & $\mathbf{1 7 . 3 3} \pm \mathbf{1 . 4 9}$ & $\mathbf{7 . 6} \pm \mathbf{1 . 3 2 9}$ & $<\mathbf{0 . 0 0 1}$ \\
\hline Duration & $\mathbf{3 4 9} \pm \mathbf{2 5 . 9 1}$ & $\mathbf{5 9 0 . 3 3} \pm \mathbf{2 . 9 7}$ & $<\mathbf{0 . 0 0 1}$ \\
\hline
\end{tabular}

\begin{tabular}{|l|c|c|c|}
\hline \multicolumn{4}{|c|}{ Table 3 Motor Characteristics of Brachial Plexus Blockade } \\
\hline $\begin{array}{l}\text { motor characteristics } \\
\text { (min) }\end{array}$ & $\begin{array}{c}\text { Group MS }(\mathbf{n}=\mathbf{3 0}) \\
(\text { mean } \pm \text { SD) }\end{array}$ & $\begin{array}{c}\text { Group } \mathbf{D}(\mathbf{n}=\mathbf{3 0}) \\
(\text { mean } \pm \text { SD })\end{array}$ & P value \\
\hline Onset & $\mathbf{2 1 . 3 3} \pm \mathbf{1 . 7 5}$ & $\mathbf{1 0 , 2} \pm \mathbf{1 . 6 7}$ & $<\mathbf{0 . 0 0 1}$ \\
\hline Duration & $\mathbf{2 8 8 . 6 6} \pm 26.35$ & $\mathbf{3 9 8 . 6 6} \pm \mathbf{2 6 . 4 8}$ & $<\mathbf{0 . 0 0 1}$ \\
\hline
\end{tabular}




\begin{tabular}{|l|c|c|c|}
\hline \multicolumn{4}{|l|}{ Table 4 duration of effective analgesia } \\
\hline Variables & $\begin{array}{c}\text { Group MS }(\mathbf{n}=\mathbf{3 0}) \\
(\text { mean } \pm \text { SD })\end{array}$ & $\begin{array}{c}\text { Group D }(\mathbf{n}=\mathbf{3 0}) \\
(\text { mean } \pm \text { SD })\end{array}$ & P value \\
\hline $\begin{array}{l}\text { Effective analgesia } \\
(\mathrm{min})\end{array}$ & $\mathbf{3 8 6} \pm \mathbf{3 0 . 6 9}$ & $\mathbf{6 6 4 . 3 3} \pm \mathbf{3 0 . 0 2}$ & $<\mathbf{0 . 0 0 1}$ \\
\hline
\end{tabular}

- Onset - It was taken as time duration from the end of injection to decreased thumb movement

- Duration - It was taken as time duration from complete motor block to reappearance of thumb movement.

Duration of post-operative analgesia was taken as time duration from the onset of sensory block to first rescue analgesic requested by the patient at visual analog scale $(\mathrm{VAS}) \geq 4$.

If the block was considered to be adequate, surgeons were allowed to apply tourniquet and start the surgery. If the block was considered to be inadequate for surgery, the patient was given general anesthesia and excluded from the study.

Patients were monitored for nausea, vomiting, hypersensitivity reaction, any sign of cardiovascular system (CVS) or central nervous system (CNS) toxicity, evidence of pneumothorax, hematoma, and post-block neuropathy during the study.
The patients were educated regarding reporting of pain using VAS which is of 10 points where " 0 " indicates no pain and "10" indicates worst possible pain.

In post-operative period, when patient complained of pain at operative site, inj. diclofenac sodium 1.5 $\mathrm{mg} / \mathrm{kg}$ intravenously and the time for rescue analgesia noted (VAS $\geq 4$ ).

Both groups were compared for complete onset time and total duration of sensory blockade, motor blockade, and total duration of analgesia. All the data were filled in pro forma and were statistically analyzed by GraphPad instant 3.0 software. Intergroup comparison of the quantitative data among the different groups was done using the unpaired $t$-test and of the qualitative data was done by Chi-square test. Intragroup comparison of the quantitative data was done using unpaired $t$ test where baseline value was used as control. $P<$ 0.05 was taken as statistically significant.

\section{Postoperative mean heart rate}

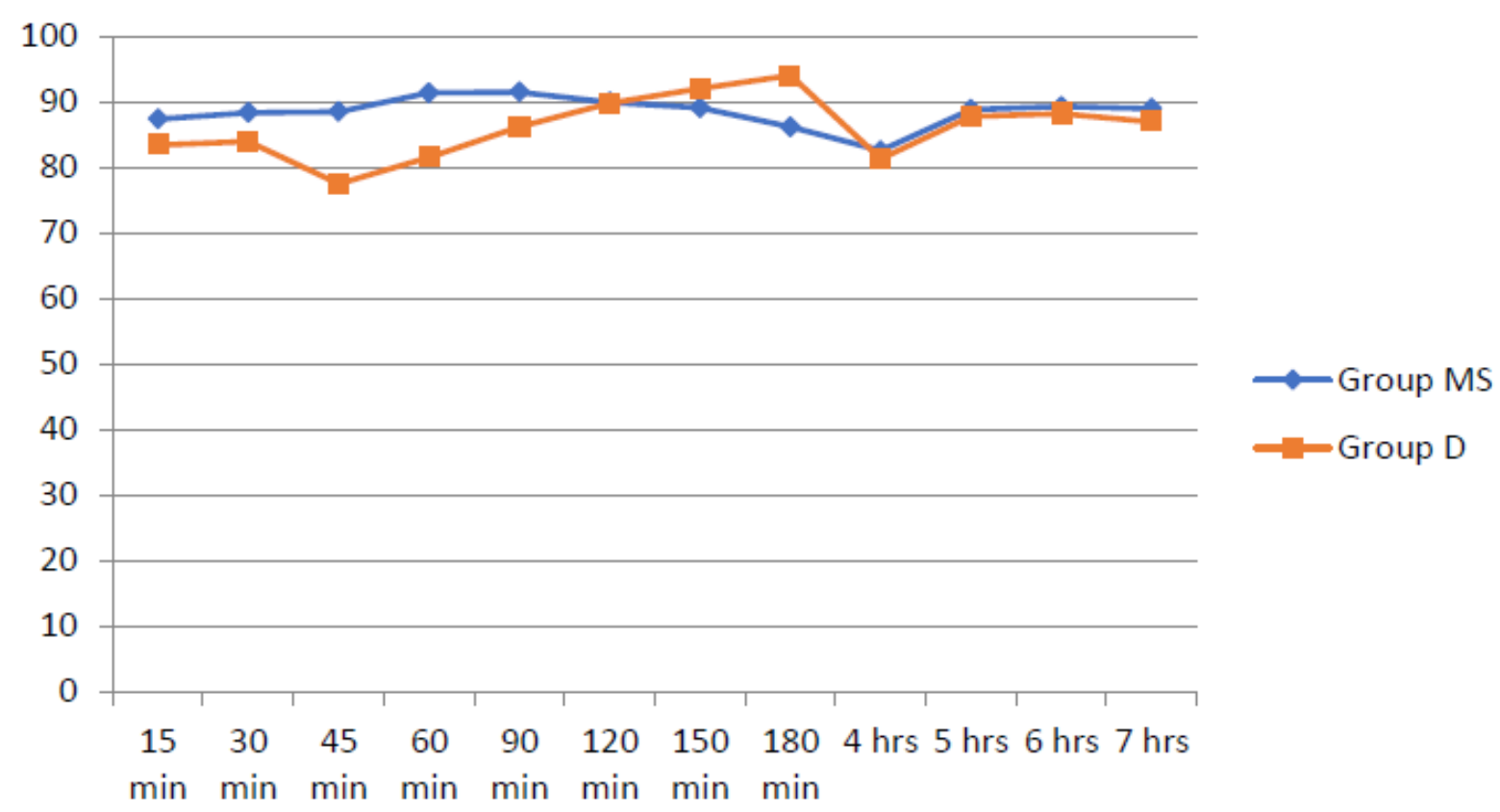




\section{Postoperative mean systolic blood pressure}

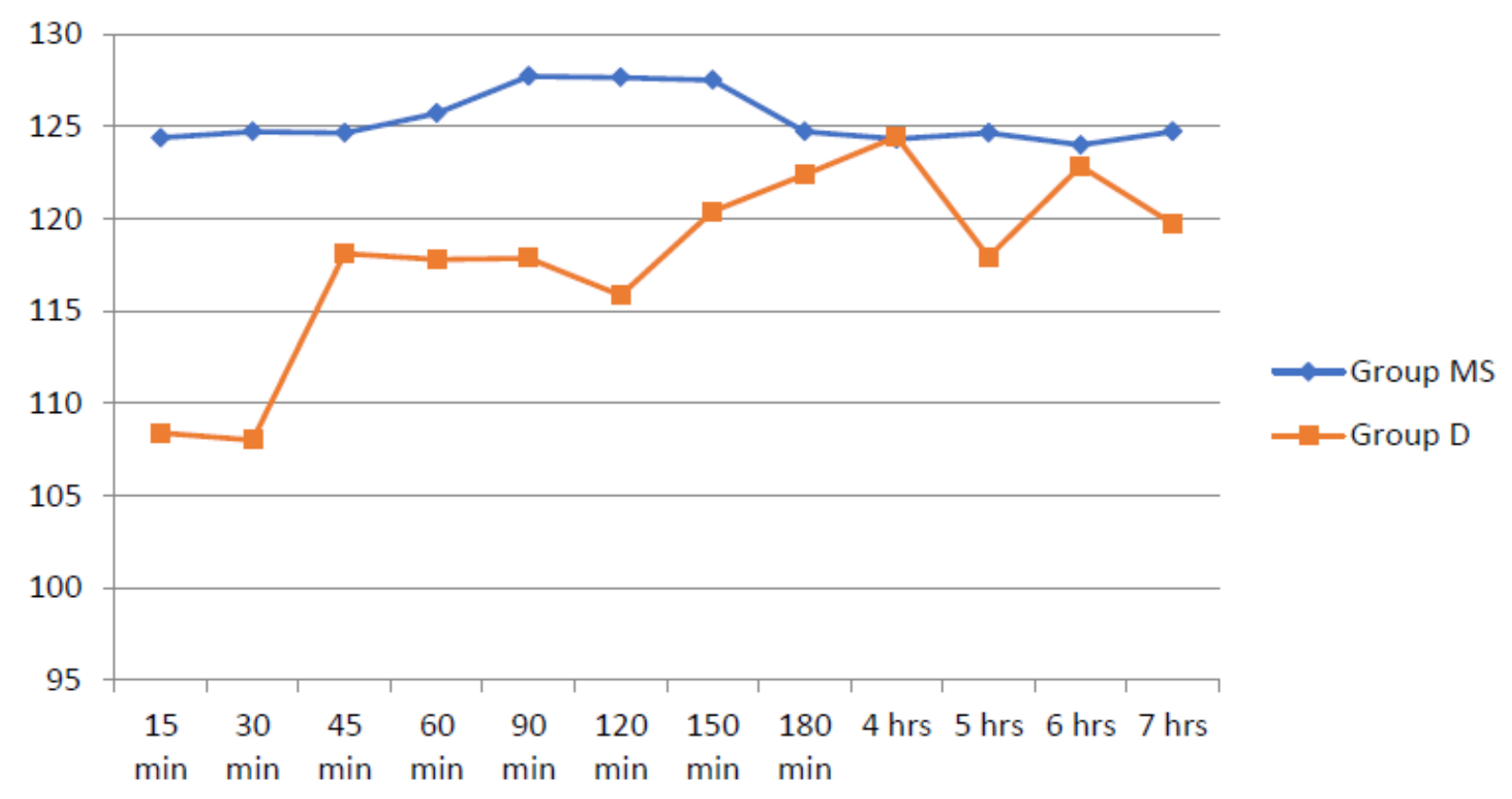

Post-operative diastolic blood pressure

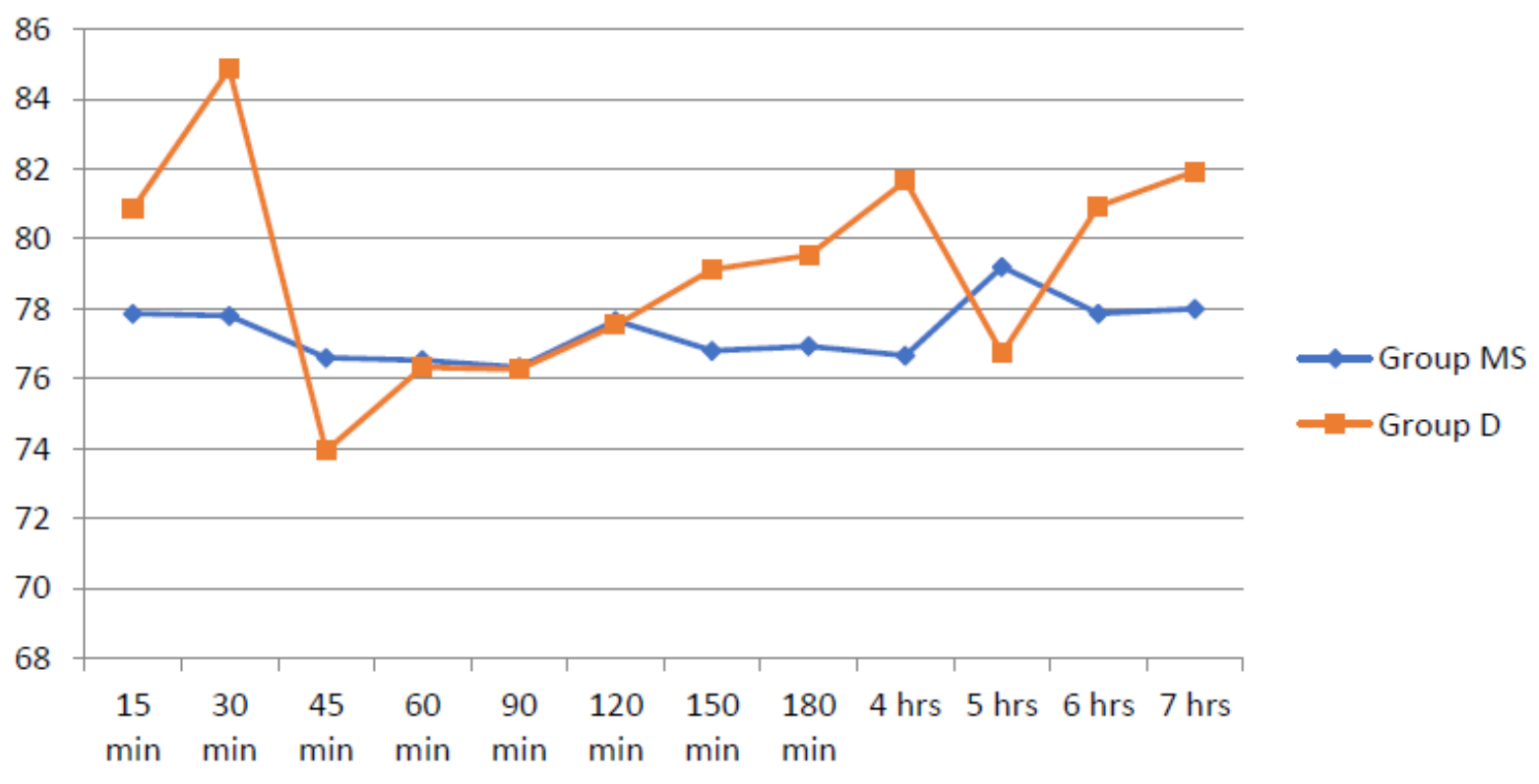




\section{Comparison of sedation score in Group MS (number of patients)}

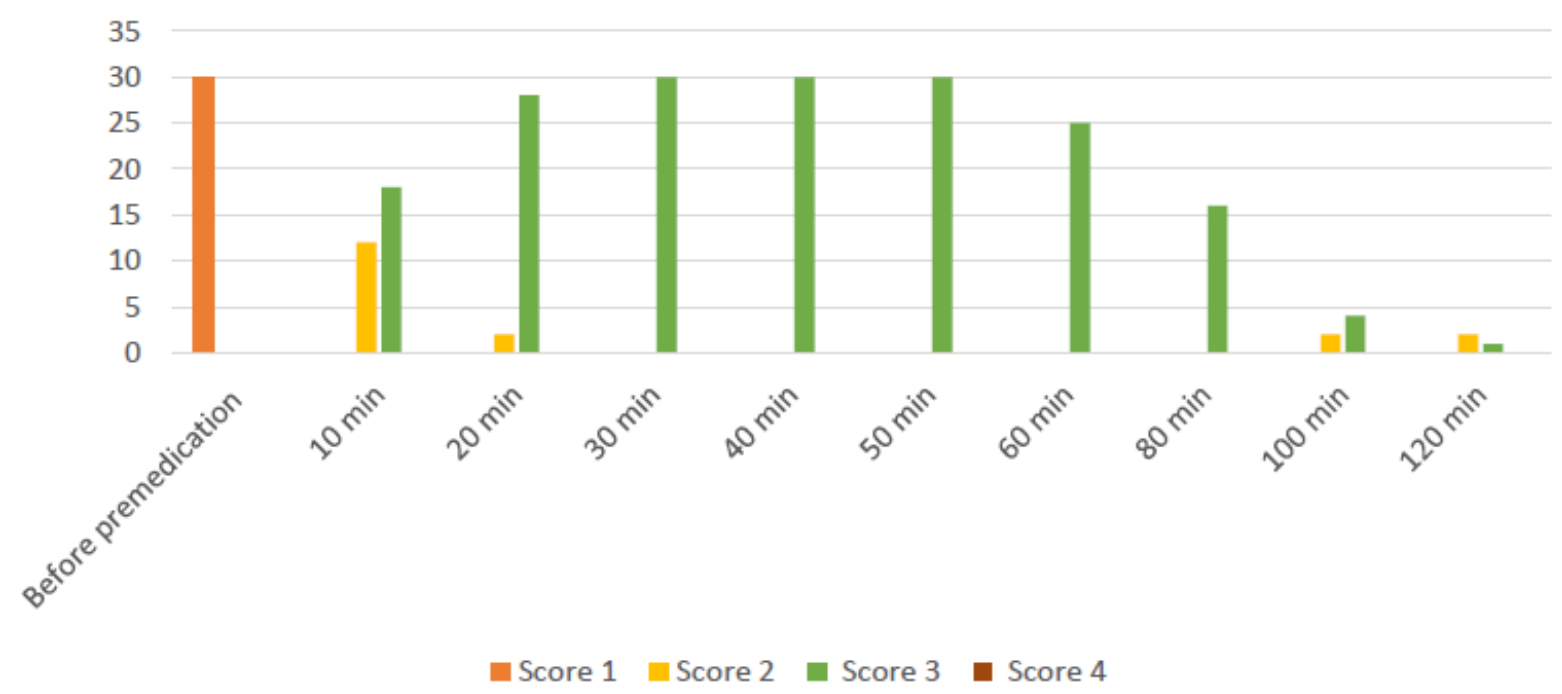

\section{Comparison of sedation score in Group D (number of patients)}

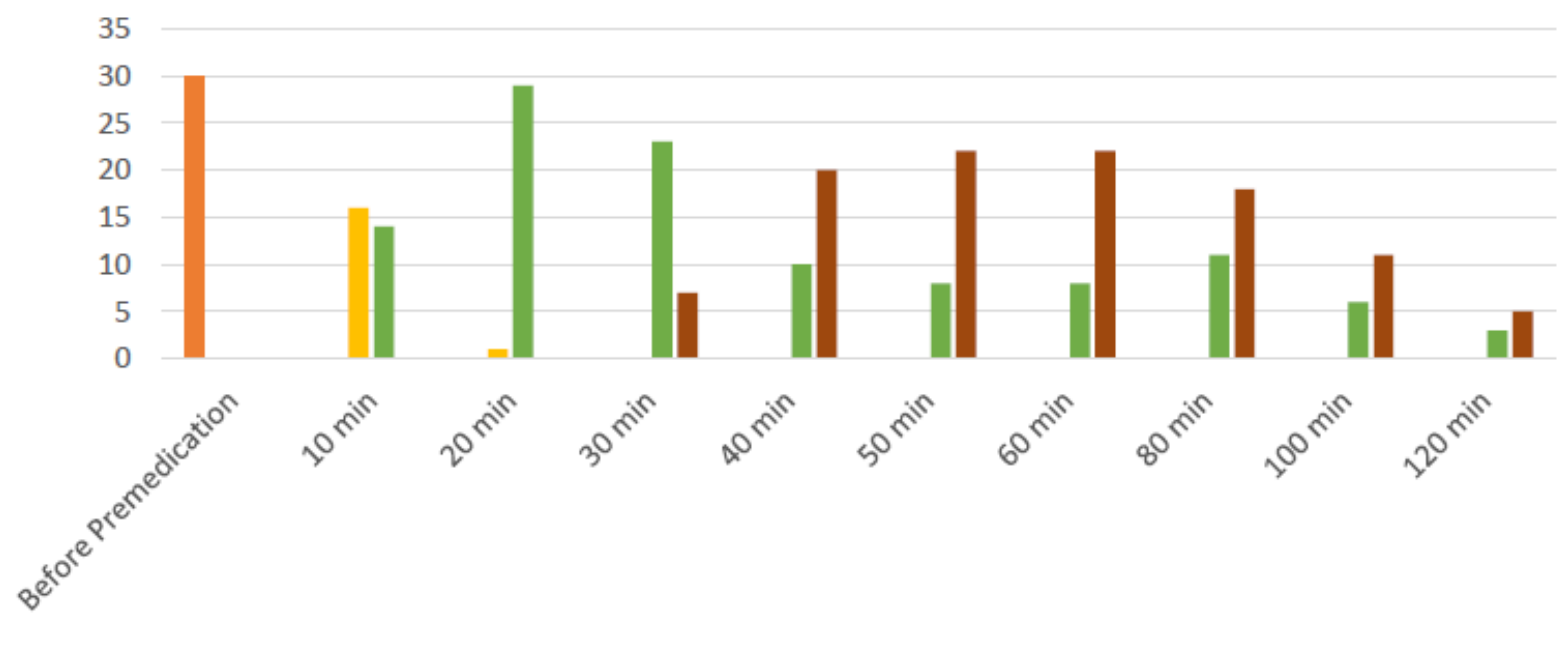

a Score $1 \square$ Score $2 \square$ Score $3 \quad$ Score 4

\section{Results}

As shown in Table 1, demographic data in terms of age, sex, and weight were comparable in both the groups $(P>0.05)$ is not statistically significant. The duration of surgery was also comparable in both groups $(P>0.05)$.

On comparing both the groups, Group D produced statistically significant earlier onset and peak with prolonged duration of sensory blockade as compared to Group MS $(P<0.0001)$ [Table 2].
On comparing both the groups, Group D produced statistically significantly earlier onset and peak with prolonged duration of motor blockade as compared to Group MS $(P<0.0001)$ [Table 3].

On comparing both the groups, Group D produced significantly prolonged the duration of analgesia as compared to Group MS $(P<0.0001)$ [Table 4]. 


\section{Discussion}

Regional anesthesia is practiced in most developing countries. Regional nerve blocks are based on the concept that pain is conveyed by nerve fibers, which are amenable to interruption anywhere along their pathway. innfraclvicular blocks are performed at the level of the brachial plexus trunks. As with other fields, regional anesthesia has undergone major developments both in technique and drugs availability. Gradually, ropivacaine was introduced into clinical practice. Local anesthetics alone for infraclavicular brachial plexus block provide good operative conditions but have a shorter duration of post-operative analgesia. Recently, dexmeditomidine has been reported as an effective adjuvant for regional anesthetic agents. On reviewing literature, the present study was undertaken to compare analgesia and effectiveness regarding onset and duration of complete motor and a sensory block of $0.5 \%$ ropivacaine alone versus $0.5 \%$ ropivacaine with dexmeditomidine or magnesium sulphate in patients undergoing infraclavicular brachial plexus block.

\section{Onset}

The mean time of onset of sensory blockade (7.6 \pm $1.329 \mathrm{~min}$ in Group D vs. $17.33 \pm 1.49 \mathrm{~min}$ in Group MS) and the motor blockade (10.2 \pm 1.67 min in Group D vs. $21.33 \pm 1.75$ min in Group MS) was faster in Group D compared to Group MS and was statistically significant

In 2017, SANDHYA AGARWAL, RITU AGGARWAL, PRAVEEN GUPTA ${ }^{[4]}$ compared the effects of adding DEXMEDETOMIDINE to a $30 \mathrm{ml}$ solution of $0.325 \%$ Bupivacaine in supraclavicular brachial plexus block. Control group $\mathrm{S}(n=25)$ received $30 \mathrm{ml}$ of $0.325 \%$ bupivacaine with $1 \mathrm{ml}$ of isotonic sodium chloride solution. Study group SD $(n=25)$ received $30 \mathrm{ml}$ of $0.325 \%$ bupivacaine and $1 \mathrm{ml}(100 \mu \mathrm{g})$ of DEXMEDETOMIDINE. The mean onset time for sensory blocks in group SD and group $\mathrm{S}$ were $13.2 \pm 1.8$ and $19.0 \pm 3.2$ minutes respectively. The mean onset time for complete motor block in group SD and group S were $16.2 \pm 1.8$ and $22.7 \pm$ 2.8 mins respectively. There was statistically significant difference with $P<0.05$ between study groups as regards to onset of complete motor block.

In 2018, WEI DAI, MM, MAOCAI TANG, MM, KAIHUA $\mathrm{HE}^{[5]}$ conducted a meta-analysis for randomized controlled trials for the effect and safety of DEXMEDETOMIDINE added to ROPIVACAINE in brachial plexus block. 12 RCTs were included in the meta-analysis ( $n=671$ ). As an adjuvant to ROPIVACAINE, DEXMEDETOMIDINE significantly reduced the onset time of sensory blockage (mean difference [MD], 3.86 minutes, 95\% CI_5.45 to_2.27 minutes; $\mathrm{I} 2=85 \%$ ) andthe onset time of motor (MD,_5.21 minutes; 95\% CI_7.48 to_2.94 minutes; I2=94\%). DEXMEDETOMIDINE added to ROPIVACAINE in BPB has a better analgesia effect.

\section{Duration of Sensory and Motor Blockade}

In the present study, the mean duration of the sensory blockade $(590.33 \pm 27.97 \mathrm{~min}$ in Group D vs. $349 \pm 25.91$ in Group MS) and the motor blockade $(398.66 \pm 26.48 \mathrm{~min}$ in Group D vs. $288.66 \pm 26.35 \mathrm{~min}$ in Group MS) was also prolonged and was statistically significant $(P$ $<0.001$ )

In 2017, SANDHYA AGARWAL, RITU AGGARWAL, PRAVEEN GUPTA ${ }^{[4]}$ compared the effects of adding DEXMEDETOMIDINE to a $30 \mathrm{ml}$ solution of $0.325 \%$ BUPIVACAINE in supraclavicular brachial plexus block. Control group $\mathrm{S}(n=25)$ received $30 \mathrm{ml}$ of $0.325 \%$ bupivacaine with $1 \mathrm{ml}$ of isotonic sodium chloride solution. Study group SD $(n=25)$ received $30 \mathrm{ml}$ of $0.325 \%$ bupivacaine and $1 \mathrm{ml}(100 \mu \mathrm{g})$ of DEXMEDETOMIDINE. The mean duration time for sensory block for group SD and group S were $755.6 \pm 126.8$ and $234.8 \pm 47.9$ mins respectivelyThe mean duration time for motor block for group SD and group S were 702.0 \pm $112.6 \mathrm{~min}$ and $208.0 \pm 22.7$ mins respectively. 
There was statistically significant difference. In 2018, WEI DAI, MM, MAOCAI TANG, MM, KAIHUA $\mathrm{HE}^{[5]}$ conducted a meta-analysis for randomized controlled trials for the effect and safety of DEXMEDETOMIDINE added to ROPIVACAINE in brachial plexus block. 12 RCTs were included in the meta-analysis $(n=671)$. The addition of DEXMEDETOMIDINE increased the duration of sensory block significantly of 228.70 minutes in average compared with the group with ROPIVACAINE treated alone (MD, 228.70 minutes; 95\% CI 187.87-269.52 minutes, $\mathrm{I} 2=93 \% ; \mathrm{P}<.0001)$ and increased duration of motor block (MD, 303.04 minutes; 95\% CI 228.84-377.24 minutes; I2=86\%).

\section{Duration of Analgesia}

In the present study, the duration of analgesia was prolonged in Group D $(664.33 \pm 30.02 \mathrm{~min})$ as compared with Group MS (386 $\pm 30.69 \mathrm{~min})$ which was statistically significant $(P<0.001)$.

In 2017, SANDHYA AGARWAL, RITU AGGARWAL, PRAVEEN GUPTA ${ }^{[4]}$ compared the effects of adding DEXMEDETOMIDINE to a $30 \mathrm{ml}$ solution of $0.325 \%$ Bupivacaine in supraclavicular brachial plexus block. Control group $\mathrm{S}(n=25)$ received $30 \mathrm{ml}$ of $0.325 \%$ BUPIVACAINE with $1 \mathrm{ml}$ of isotonic sodium chloride solution. Study group SD $(n=25)$ received $30 \mathrm{ml}$ of $0.325 \%$ bupivacaine and $1 \mathrm{ml}$ $(100 \mu \mathrm{g})$ of DEXMEDETOMIDINE. The mean duration of analgesia (DOA) for group SD was $776.4 \pm 130.8 \mathrm{~min}$, it was $241.4 \pm 51.2 \mathrm{~min}$ for group S. Duration of analgesia was significantly longer in group SD than group $\mathrm{S}(P<0.001)$. There was statistically significant difference with $P<0.05$ between study groups as regards to total duration of analgesia.

\section{Sedation Score}

The data from our study reveals that sedation score was higher in Group D than in Group MS. In our study, the mean sedation score in Group MS and Group D was $2.35532 \pm 0.19636$ and $2.63404 \pm 0.28792$ minutes respectively. After applying $\mathrm{T}$ test, the difference was statistically highly significant $(\mathrm{p}<0.001)$. These results are comparable to other studies-

IN 2015, KWONY, HWANGS, LEE JJ ET $\mathrm{AL}^{[6]}$ conducted a study with the aim to evaluate the sedative effect of DEXMEDETOMIDINE added to ROPIVACAINE for supraclavicular brachial plexus block (BPB) using the bispectral index (BIS). Each patient was randomly assigned to receive either $40 \mathrm{ml}$ of ROPIVACAINE0.5\% with $0.01 \mathrm{ml} / \mathrm{kg}$ normal saline (Group $\mathrm{R}, \mathrm{n}=30$ ), or $40 \mathrm{ml}$ of ROPIVACAINE0.5\% with $1 \mu \mathrm{g} / \mathrm{kg}$ DEXMEDETOMIDINE (Group RD, $\mathrm{n}=30$ ) in a double-blinded fashion. A supraclavicular brachial plexus block was performed.

The BIS was significantly lower than that for Group $\mathrm{R}$ throughout the monitoring period (Greenhouse-Geisser-adjusted P value $(\varepsilon=0.429)$ $<0.001)$.

It was concluded that DEXMEDETOMIDINE added to ROPIVACAINE for brachial plexus block induced sedation that corresponds to a BIS value of 60 from which patients are easily awakened in a lucid state resulting in better cooperation with the surgical team during surgery and recovery.

\section{VAS SCORE}

The data from our study reveals that VAS score was higher in Group MS than in Group D. In our study, the mean sedation score in Group MS and Group D was $2.06424 \pm 0.7614$ and $1.81136 \pm$ 0.53472 minutes respectively. After applying $\mathrm{T}$ test, the difference was statistically highly significant $\quad(p<0.001)$. These results are comparable to other studies-

In 2016, MOHAMED M. ABU ELYAZED AND MONA M. MOGAHED ${ }^{[2]}$ conducted a study for Comparison of MAGNESIUM SULPHATE and DEXMEDETOMIDINE as an Adjuvant to $0.5 \%$ ROPIVACAINE in INFRACLAVICULAR BRACHIAL PLEXUS BLOCK. This was a prospective randomized double blinded controlled study. Postoperative VAS was lower in MAGNESIUM SULPHATE and 
DEXMEDETOMIDINE groups than that in ROPIVACAINE group. At 12-hour postoperative, the VAS was significantly lower in DEXMEDETOMIDINE group than MAGNESIUM SULPHATE group $(P=0.005)$.

\section{Hemodynamic Changes}

In our study, we have observed statistically significant changes in heart rate, SBP, DBP and Mean Arterial Pressure during the intraoperative and postoperative period. However, none of our patients required any anticholinergic treatment or any vasopressor support during the study period. These results are comparable to other studies.

\section{Complications}

There was no incidence of headache, nausea, vomiting, hypotension, bradycardia, chest pain, coughing, convulsion and respiratory depression, and procedure-related complication. There were no CNS and CVS toxicity seen in either group in our study.

\section{Conclusion}

Based on the present clinical comparative study and a short review of past literature, I conclude that DEXMEDITOMEDINE as an adjuvant to ROPIVACAINE compared to MAGNESIUM SULPHATE as an adjuvant to ROPIVACAINE in INFRACLAVICULAR BRACHIAL BLOCK for upper limb surgery fastens the onset time for sensory \& motor block and prolongs the duration of sensory \& motor blocks with longer duration of postoperative analgesia, causes decrease in need of rescue analgesia in patients with no side effects. DEXMEDETOMIDINE as an adjuvant to ROPIVACAINE has better sedation and postoperative analgesia than MAGNESIUM SULPHATE as an adjuvant to ROPIVACAINE in INFRACLAVICULAR BRACHIAL BLOCK.
Bibliography

1. Morgan \& Mikhail's clinical anaesthesiology $5^{\text {th }}$ edition section 4 ch46, peripheral nerve block.

2. Elyazed MM, Mogahed MM. Comparison of magnesium sulfate and dexmedetomidine as an adjuvant to $0.5 \%$ ropivacaine in infraclavicular brachial plexus block. Anesth Essays Res 2018;12:109-15.

3. https://www.nysora.com/regionalanesthesia-for-specific-surgicalprocedures/upper-extremity-regionalanesthesia-for-specific-surgicalprocedures/anesthesia-and-analgesia-forelbow-and-forearmprocedures/infraclavicular-brachial-plexusblock-2/

4. Agarwal S, Aggarwal R, Gupta P. Dexmedetomidine prolongs the effect of bupivacaine in supraclavicular brachial plexus block. J AnaesthesiolClinPharmacol2014;30:36-40.

5. Wei Dai, MMa, Maocai Tang, MMb, Kaihua He, The effect and safety of dexmedetomidine added to ropivacaine in brachial plexus block A meta-analysis of randomized controlled trials. Medicine (2018) 97:41(e12573).

6. Kwon Y, Hwang S, Lee J J, Kim H J. The effect of Dexmedetomidine as an adjuvant to Ropivacaine on the bispectral index for supraclavicular brachial plexus block. Korean J Anesthesiol 2015; 68: 32-6. 